\title{
Streptococcus pneumoniae-induced purpura fulminans in a woman with functional asplenia
}

\author{
Jeremy M. Wojtowicz, MD*; Graham Longden Jones, $\mathrm{PhD}, \mathrm{MD}^{\dagger}$
}

\section{ABSTRACT}

Purpura fulminans is a rare complication of septic shock, often associated with Streptococcus pneumoniae. Patients with anatomic or functional asplenia are at increased risk for infection because of impairment of their ability to defend against encapsulated pathogens. We report the case of a previously healthy, unimmunized 33-year-old female with functional asplenia who presented in septic shock and purpura fulminans and died in spite of maximal resuscitative measures. The clinical presentation, diagnosis, and management of purpura fulminans are reviewed. Purpura fulminans is a rare condition that requires early diagnosis and aggressive management by emergency physicians.

\section{RÉSUMÉ}

Le purpura fulminant est une complication rare du choc septique, souvent associé à une infection à Streptococcus pneumoniae. Les personnes atteintes d'asplénie anatomique ou fonctionnelle sont prédisposées aux infections en raison de l'incapacité de l'organisme de se défendre contre les agents encapsulés. II sera ici question du cas d'une femme de 33 ans, non vaccinée, auparavant en bonne santé, mais souffrant d'asplénie fonctionnelle, qui est arrivée en état de choc septique, accompagné de purpura fulminant, et qui est morte malgré toutes les mesures possibles de réanimation. Nous passerons en revue le tableau clinique du purpura fulminant ainsi que le diagnostic et la prise en charge de la maladie; il s'agit d'une affection qui appelle un diagnostic précoce et une prise en charge énergique par les urgentologues.

Keywords: purpura fulminans, splenectomy, Streptococcus pneumoniae

Purpura fulminans (PF) is a life-threatening condition typically affecting individuals with impaired immune systems, including functional asplenia. It is an uncommon but dramatic manifestation of severe sepsis associated with the rapid development of disseminated intravascular coagulation (DIC) and circulatory failure as a result of simultaneous intravascular hemorrhage and thrombosis. ${ }^{1}$ $\mathrm{PF}$ is frequently fatal, with mortality rates exceeding $40 \%$. The rash of PF initially appears as well-demarcated erythematous macules that rapidly progress to areas of hemorrhagic necrosis, often surrounded by an erythematous border. ${ }^{2}$ Hemorrhage into these necrotic areas causes the lesions to become painful, dark, and elevated and may be associated with vesicle or bulla formation. ${ }^{2}$ Survivors often suffer significant morbidity, including tissue necrosis requiring skin grafts and amputation. ${ }^{1}$

Functional asplenia, or hyposplenism, occurs when the spleen is anatomically present but has impaired reticuloendothelial functioning. Individuals with asplenia are at increased risk for sepsis, with an incidence of 0.9 to $3.2 \% .^{3,4}$ Sepsis in individuals with asplenia is frequently fatal, with mortality rates of 50 to $70 \% .^{5}$ Infections in people with asplenia are most often secondary to encapsulated bacteria, namely Streptococcus pneumoniae, Haemophilus influenzae type b, and Neisseria meningitidis, with $S$. pneumoniae accounting for 50 to $90 \%$ of cases. ${ }^{6,7}$

We report a case of a 33-year-old female with functional asplenia who presented with PF secondary to $S$. pneumoniae. The clinical presentation, diagnosis, and management of PF are reviewed.

\section{CASE REPORT}

A 33-year-old female with a complaint of chest pain and shortness of breath was brought to the emergency department (ED) by ambulance. Although distressed,

From the Divisions of *Emergency Medicine and tRespirology, McMaster University, Hamilton, ON.

Correspondence to: Dr. Jeremy Wojtowicz, Department of Emergency Medicine, Hamilton General Hospital, 237 Barton Street East, Hamilton ON L8L 2X2; jmwojtow@hotmail.com.

This article has been peer reviewed.

(c) Canadian Association of Emergency Physicians

CJEM 2014;16(4):339-342

DOI 10.2310/8000.2013.130990 
the patient was able to give a brief history. She stated that the previous evening, she had felt nauseated and vomited but had no other symptoms. In the morning, she awoke with chest pain, shortness of breath, rash, and a feeling of impending doom. Review of systems was negative: specifically, she denied headache, photophobia, neck stiffness, cough, fever, hemoptysis, urinary symptoms, abdominal pain, travel, or sick contacts. She had surgery for an anal fistula 2 months prior to presentation; however, the patient denied any other medical history. Subsequent review of her medical records revealed that she had previously been diagnosed with functional asplenia. This diagnosis was based on the presence of a small spleen on a sonogram and Howell-Jolly bodies in her peripheral blood smear. There was no record of immunization against encapsulated organisms, including $S$. pneumoniae, and no way for us to confirm immunization status or why immunization may not have occurred.

On examination, the patient was distressed. Her initial vital signs were as follows: heart rate 145 beats/ min, respiratory rate 30 breaths/min, and temperature $37.6^{\circ} \mathrm{C}\left(99.7^{\circ} \mathrm{F}\right)$. Blood pressure and oxygen saturations were unobtainable because of peripheral vasoconstriction. The most striking abnormality was that the patient had a purpuric rash covering her entire body, although the rash was initially less apparent on her abdomen and lower extremities compared to the rest of her body. There was no active external bleeding; however, there was prolonged oozing from sites of venipuncture. She had increased work of breathing and accessory muscle use, as well as bilateral crepitations on auscultation. Jugular venous pressure was flat. The remainder of her examination was normal.

Initial laboratory investigations were normal, with the following exceptions: white blood cell count $10.7 \times$ $10^{9} / \mathrm{L}$, bands $2.4 \times 10^{9} / \mathrm{L}$, neutrophils $5.6 \times 10^{9} / \mathrm{L}$, platelets $80 \times 10^{9} / \mathrm{L}$, creatinine $232 \mu \mathrm{mol} / \mathrm{L}$, anion gap 25 , lactate $13.7 \mathrm{mmol} / \mathrm{L}$, venous $\mathrm{pH} \mathrm{7.01}$, carbon dioxide partial pressure $52 \mathrm{~mm} \mathrm{Hg}$, bicarbonate $13 \mathrm{mmol} / \mathrm{L}$, base excess $-19 \mathrm{mmol} / \mathrm{L}$, fibrinogen $<$ $0.2 \mathrm{~g} / \mathrm{L}$, partial thromboplastin time $\geq 150$ seconds, and international normalized ratio 2.5. Howell-Jolly bodies were present on the peripheral smear. Serum $\beta$-human chorionic gonadotropin was negative. Urinalysis and the initial chest radiograph were normal. A second chest radiograph taken a short time later showed pulmonary edema consistent with acute respiratory distress syndrome, but there were no signs of pneumonia. An electrocardiogram demonstrated sinus tachycardia.

Due to her critical condition, the patient was intubated and started on vasopressors. She was aggressively volume resuscitated with normal saline, receiving $5 \mathrm{~L}$ in the ED. In addition, she received vancomycin $(1 \mathrm{~g})$ and ceftriaxone $(2 \mathrm{~g})$. These antibiotics were infused within 15 minutes of the patient's arrival in the ED. She subsequently received piperacillin-tazobactam $(4.5 \mathrm{~g})$ for the possibility of intra-abdominal sepsis given her recent surgery. The patient was transferred to the intensive care unit (ICU) with a diagnosis of DIC and PF, secondary to septic shock.

In the ICU, she was given levofloxacin and clindamycin and started on an activated protein $\mathrm{C}$ infusion; however, this was stopped when the patient developed gastric bleeding. Blood culture grew grampositive cocci in pairs and chains after 6 hours of incubation. While she was in the ICU, her condition deteriorated. Maximum resuscitative measures were attempted, including massive fluid resuscitation with crystalloids, colloids, and blood products, as well as aggressive administration of vasopressors and inotropes. Despite these measures, the patient expired approximately 12 hours after arriving at the ED. Culture and sensitivity available postmortem confirmed $S$. pneumoniae sensitive to penicillins and levofloxacin.

\section{DISCUSSION}

$\mathrm{PF}$ is a hematologic emergency in which there is skin necrosis and DIC. ${ }^{8} \mathrm{PF}$ is a rare but frequently fatal manifestation of sepsis more often seen in adults with hyposplenism or in individuals with deficiency of protein C or protein S. ${ }^{8,9}$ It is often difficult to identify the source of infection, and there is often only a short, nonspecific prodrome before PF manifests. The dramatic appearance of the patient is related to hemorrhagic infarction of the skin as part of the manifestation of multiorgan system failure. ${ }^{8}$

Functional asplenia may occur as a primary, congenital abnormality or arise secondary to other conditions, including sickle cell disease and other hemoglobinopathies, autoimmune diseases, alcoholic liver disease, and gastrointestinal diseases, such as celiac disease. ${ }^{10,11}$ Howell-Jolly bodies (small round or oval bodies representing nuclear remnants in erythrocytes) on the peripheral blood smear are indicative of splenic dysfunction and are present in the blood of all individuals with 
hyposplenia, except those with only mild impairment of splenic function. ${ }^{12}$ Additional hematologic and nuclear investigations, such as radioisotope labeling with technetium, can be performed to confirm the diagnosis of hyposplenism. ${ }^{12}$

The majority of the literature pertaining to $\mathrm{PF}$ exists as case reports and series rather than systematic reviews or clinical trials. Chalmers and colleagues recently reviewed this literature in an attempt to generate recommendations for the diagnosis and management of PF. ${ }^{8}$ Most of the following discussion is based on their conclusions.

The differential diagnosis for PF includes immune thrombocytopenic purpura, thrombotic thrombocytopenia purpura, Henoch-Schönlein purpura, and warfarin-induced skin necrosis. ${ }^{8}$ With the exception of warfarin-induced necrosis, these differential diagnoses are not usually associated with tissue necrosis, and the correct diagnosis can usually be determined based on clinical and laboratory features. ${ }^{13}$

PF should be suspected based on the clinical appearance of the patient, and laboratory investigations can be used to confirm the diagnosis. Typically, laboratory testing demonstrates the findings of DIC (increased clotting times, thrombocytopenia, presence of fibrin degradation products, and low levels of fibrinogen), as well as markedly reduced levels of protein $\mathrm{C}$ or protein $\mathrm{S} .{ }^{8}$

Management of PF should focus on the underlying etiology, which is severe sepsis in most adults. Appropriate hemodynamic resuscitation ${ }^{14}$ and early antibiotic coverage should be the initial focus of management.

Our patient received numerous antibiotics during her clinical course. S. pneumoniae and N. meningitidis were suspected to be the most likely pathogens. However, other organisms could not be excluded, and antibiotic coverage was kept broad. The patient was initially given vancomycin and ceftriaxone as coverage against $N$. meningitidis, S. pneumoniae, gram-negative bacilli, including H. influenzae, and Staphylococcus aureus. She was given a single dose of piperacillin-tazobactam to cover possible intra-abdominal sepsis secondary to her recent abdominal surgery, although this was believed to be an unlikely etiology, and the piperacillin-tazobactam was subsequently discontinued. The patient was also treated with levofloxacin to cover possible penicillinresistant $S$. pneumoniae.

The broad-spectrum antibiotics used in our patient's management are consistent with current sepsis guidelines. ${ }^{15}$ These guidelines advocate initial broad-spectrum antibiotic coverage that is reflective of local resistance patterns. ${ }^{15}$ Resistance rates for $S$. pneumoniae, the most common cause of $\mathrm{PF}$, have been measured at 8 to $26 \%$ for penicillin, 3 to $5 \%$ for thirdgeneration cephalosporins, such as ceftriaxone, and 1 to $3 \%$ for fluoroquinolones, such as levofloxacin. ${ }^{15}$ There are no documented cases of vancomycinresistant S. pneumoniae in the literature..$^{15}$ Although the guidelines do not specifically address the management of PF, they do comment on the management of the common causative pathogens. Based on these recommendations, appropriate initial antibiotic treatment for a patient with PF should include a thirdgeneration cephalosporin, such as ceftriaxone, a respiratory fluoroquinolone, such as levofloxacin, and vancomycin. This regimen will cover the likely organisms, protect against antibiotic resistance, and penetrate the central nervous system in case of meningitis. Antibiotic coverage can be modified as culture results and sensitivities become available.

Interventions to target the coagulopathy should be considered; however, evidence for these treatments is sparse, and no studies specifically examine their role in PF. Fresh frozen plasma should be used to replete consumed coagulation factors, particularly protein $\mathrm{C}$ and protein S. Platelet transfusion and cryoprecipitate should be considered for marked thrombocytopenia and hypofibrinogenemia, especially if the patient is bleeding. ${ }^{8}$ The role of anticoagulation is unclear. If administered, it should be used cautiously and preferably in consultation with Hematology. Administration of activated protein $\mathrm{C}$ (Xigris) had been shown to be beneficial in patients with $\mathrm{PF}^{16,17}$; however, it has been taken off the market by its manufacturer.

Immunization is recommended as a preventive strategy in individuals with asplenia. Guidelines recommend that hyposplenic individuals be immunized against $S$. pneumoniae, $H$. influenzae type b, and N. meningitidis. ${ }^{18}$ Although immunizations are effective for reducing the risk of infection, immunization rates remain relatively low as hyposplenia often remains undiagnosed prior to presentation with a serious infection.

\section{CONCLUSIONS}

$\mathrm{PF}$ is a dramatic manifestation of septic shock often occurring in asplenic individuals. Early recognition and aggressive interventions targeting the underlying 
etiology are necessary to improve morbidity and mortality. Broad-spectrum antibiotics targeting encapsulated bacteria should be given early in the ED course. Aggressive treatment of coagulopathy is required, although little literature exists to guide practice in an evidence-based fashion.

Competing interests: None declared.

\section{REFERENCES}

1. Jakob A, Alexandrakis E, Rompel R. Purpura fulminans secondary to respiratory infection. 7 Dtsch Dermatol Ges 2009;7:135-8.

2. Francis RB Jr. Acquired purpura fulminans. Semin Thromb Hemost 1990;16:310-25, doi:10.1055/s-2007-1002684.

3. Holdsworth R, Irving A, Cushieri A. Postsplenectomy sepsis and its mortality rate: actual versus perceived risks. Br 7 Surg 1991;78:1031-8, doi:10.1002/bjs.1800780904.

4. Bisharat N, Omari H, Lavi I, et al. Risk of infection and death among post-splenectomy patients. I Infect 2001;43: 182-6, doi:10.1053/jinf.2001.0904.

5. Melles DC, de Marie S. Prevention of infections in hyposplenic and asplenic patients: an update. Neth $7 \mathrm{Med}$ 2004;62:45-52.

6. Davidson RN, Wall RA. Prevention and management of infections in patients without a spleen. Clin Microbiol Infect 2001;7:657-60, doi:10.1046/j.1198-743x.2001.00355.x.

7. Jenks PJ, Jones E. Infections in asplenic patients. Clin Microbiol Infect 1996;1:266-72.

8. Chalmers E, Cooper P, Forman K, et al. Purpura fulminans: recognition, diagnosis and management. Arch Dis Child 2011;96:1066-71, doi:10.1136/adc.2010.199919.
9. Warner PM, Kagan RJ, Yakuboff KP, et al. Current management of purpura fulminans: a multicenter study. $\mathcal{F}$ Burn Care Rebabil 2003;24:119-26, doi:10.1097/01.BCR. 0000066789.79129.C2.

10. Basem M, Corazza G. Hyposplenism: a comprehensive review. Part 1: basic concepts and causes. Hematology 2007; 12:1-13, doi:10.1080/10245330600938422.

11. Price VE, Blanchette VS, Ford-Jones EL. The prevention and management of infections in children with asplenia or hyposplenism. Infect Dis Clin North Am 2007;21:697-710, doi:10.1016/j.idc.2007.07.002.

12. Basem M, Thawani N, Sae-Tia S, et al. Hyposplenism: a comprehensive review. Part 2: clinical manifestations, diagnosis and management. Hematology 2007;12:89-98, doi: 10.1080/10245330600938463.

13. Piette $W W$. The differential diagnosis of purpura from a morphologic perspective. Adv Dermatol 1994;9:3-23.

14. Rivers E, Nguyen B, Havstad S, et al. Early goal directed therapy in the early treatment of severe sepsis and septic shock. NEngl f Med 2001;345:1368-77, doi:10.1056/NEJMoa010307.

15. Nguyen HB, Rivers EP, Abrahamian FM, et al. Severe sepsis and septic shock: review of the literature and emergency department management guidelines. Ann Emerg Med 2006; 48:28-54.

16. Smith OP, White B, Vaughan D, et al. Use of protein $C$ concentrate, heparin and haemodiafiltration in meningococcus induced purpura fulminans. Lancet 1997;350:1590-3, doi:10.1016/S0140-6736(97)06356-3.

17. Veldman A, Fischer D, Wong FY, et al. Human protein C concentrate in the treatment of purpura fulminans: a retrospective analysis of safety and outcome in 94 pediatric patients. Crit Care 2010;14:R156, doi:10.1186/cc9226.

18. Public Health Agency of Canada. Canadian immunization guide 2006. 7th ed. Available at: http://www.phac-aspc.gc.ca/ publicat/cig-gci/pdf/cig-gci-2006_e.pdf (accessed July 25, 2011). 